\title{
Presentación del doctor Luis Bernardo Díaz de la conferencia Sicoanálisis y Derecho a cargo del doctor Leonardo Ortega*
}

Los nexos entre el derecho y la sicología no son tan recientes como pudiera creerse. El tema del estudio sicológico del delincuente o del suicida siempre estuvieron a la orden del día. La disciplina de la sicología jurídica se ha planteado en muchas ocasiones, desde una visión positivista e instrumental, temas como, el manejo de los jurados, el tratamiento penitenciario, la resocialización del delincuente o la desviación social.

A raíz de las dictaduras y los horrores del siglo $\mathrm{XX}$, como los campos de concentración o el genocidio armenio, el sicoanálisis entra a realizar importantes aportaciones.

Uno de esos investigadores en esta área que pocos abordan de la relación derechosicoanálisis, es el abogado colombiano egresado de la UIS, Leonardo Ortega, que hoy nos acompaña para honor de nuestra Facultad y del Grupo de Investigación en Justicia Social Primo Levi. Su tesis sobre derecho alternativo desde el estudio de Asffades, mereció las más altas consideraciones académicas. Se le abona su relación con los mejores grupos de sicoanalistas de Latinoamérica, en especial de Argentina, donde la disciplina es muy fuerte. Me honra que haya sido mi discípulo.

Los estudios jurídicos son bastante reducidos en la materia, y en Boyacá solo tenemos una especialización en sicología jurídica que dirige el Dr. Henry Sánchez.

El terror, el miedo, frente a la impunidad reinante, al imperio de los señores de la guerra, el terrorismo de Estado, la corrupción, entre otros, son fenómenos que deberían analizarse desde la psiquis social.

* Conferencia celebrada el 30 de abril de 2013 en la Uptc. 
Recientemente falleció -impunemente- el capo de las esmeraldas, Víctor Carranza, y en occidente nada se movía sin su autorización. Se habla de que tenía más de un millón de hectáreas de tierra y un ejército privado que lo custodiaba. Es el principal sospechoso del asesinato este año del abogado Víctor Ramírez en Tunja, por ser el apoderado de alias "Pedro Orejas", otro capo contradictor de la zona. Esta situación ha llevado a que incluso en escenarios académicos se nos dijese: "cuidado", "no hable mal del Patrón", "tiene mucho poder”, lo cual puede generar pánico y alterar los desarrollos de la propia expresión consciente.

Es lo que sucede en escenarios como la impunidad reinante, donde se sabe por ejemplo que es perdido presentar denuncias en varias zonas del país, porque sencillamente las condiciones estructurales están creadas para ello, manteniendo la injusticia. Cuando se llega, por vía de ejemplo, a altas magistraturas fruto de la politiquería, la trampa o el engaño, como ha ocurrido (verán la actual situación del magistrado recién electo en la Corte Constitucional), se produce ipso facto una negación de la legitimidad en la psiquis de las víctimas, que prefieren abstenerse de presentar denuncias sobre la base del riesgo que implica "que se le devuelva la misma" o "perder el tiempo". Esa representación puede llevar a riesgos como la venganza privada o la justicia por mano propia.

El tema de la impunidad se ampara, igualmente, en la aspiración de jueces y magistrados regionales a ascender en la escala de cargos (todo juez quiere ser magistrado algún día), por lo cual debe actuar con suma cautela en la asunción de casos difíciles, para evitar chocar contra el establecimiento judicial. Deberá aconductarse, ser dócil y fallar en contra cualquier "temeridad" que cuestione el sistema de explotación vigente o el statu quo. Temas como la demanda contra el TLC que presentamos, así como la venta irregular de la EBSA, necesariamente no pasan, por cuanto afectan políticas estructurales neoliberales de acumulación. La locomotora minero-energética será otro coto vedado -en términos de Garzón Valdésde justiciabilidad, pese a que se carguen el ecosistema.

Más grave resulta la labor punitiva e inquisitorial de personajes que prevalidos de dogmas y verdades absolutistas desde el aparato de poder o de control judicializan las expresiones contrarias a la hegemonía, como ocurre con el jefe del Ministerio Público, caso en el que recientemente el Dr. Daniel Prado manifestó no contar con garantías para la defensa de su representado, nada más ni nada menos que el alcalde Gustavo Petro. La destitución y muerte política y civil de Piedad Córdoba y de Guillermo Asprilla prevén un destino no muy halagüeño para el burgomaestre capitalino, a pesar de que la intención era muy positiva: desmontar el oligopolio que ha manejado durante décadas las basuras (donde, incluso, hay un paramilitar, según lo dijo Petro). 
Otro de los mitos consiste en demandar a las instituciones donde uno trabaja, pues para las mentalidades sumisas es como demandar a la madre, "morder el brazo del amo que lo alimenta" o "patear la lonchera". Ello crea un sentimiento de impotencia que se traduce en el patrocinio de las más abyectas formas de dominio y esclavismo. Generalmente quien lo hace será llevado al patíbulo por "traidor". Nos sucedió en la UIS, donde el tiempo nos dio la razón, pero el autoritarismo sigue mandando, llegándose hasta diseñar el "Plan Pistola" desde la rectoría, que consistía en establecer la lista de los opositores para pasárselos al paramilitar de turno. Él sabría qué labor de limpieza social debería cumplir.

Otro escenario de constricción ciudadana lo constituye la afiliación sindical en Colombia, que tiene records internacionales en el crimen de sindicalistas. Los trabajadores prefieren abstenerse de afiliarse a la organización sindical, en la medida en que van a ser estigmatizados, censurados y aislados por los patronos, cuando no amenazados y exterminados. Personalmente fui objeto de amenazas de muerte en 2008, por mi ejercicio de presidente del sindicato de la Universidad. Desde luego la denuncia quedó en la impunidad y el Fiscal del caso me dijo que esas amenazas eran "normales". Este jueves, que vendrá la jefa de la Oficina de Víctimas de Presidencia, habrá que preguntarle qué pasó con esa investigación engavetada, como muchas.

Para Zaffaroni, los principales crímenes se cometen desde la estructura del aparato estatal y esa criminalidad amenaza con agigantarse desde una organización hegemónica que comprenda y someta a la universalidad de los aparatos estatales. Agrega: "Los crímenes de masa son cometidos por un poder punitivo descontrolado, o sea, que las propias agencias del poder punitivo cometen los crímenes más graves cuando operan sin contención. Es verdad que muchos de estos crímenes se imputan a fuerzas militares, pero también es cierto que, fuera de los casos en que son auténticos crímenes de guerra, estas fuerzas los han cometido operando funciones materialmente policiales y no bélicas".

La fuerza hegemónica internacional, en especial luego de los sucesos de las Torres Gemelas, construye una dicotomía amigo-enemigo, que lleva a Bush a decir: "o se está con nosotros o se está contra nosotros”. Uribe Vélez es la versión criolla de esta falacia.

Para el autor argentino, la ciencia penal y criminológica no tiene instrumentos conceptuales para dar cuenta de los crímenes masivos que se generan y cometen desde el dominio del aparato de Estado. Su conceptualización está limitada a informar de la producción delictiva de los particulares contra las reglas establecidas (positivismo penal) por el Estado. Morrison, el abogado defensor de Luis XVI, diría: “Un Rey debe reinar o morir, pero nunca ser juzgado” (caso Juan Carlos de Borbón). 
Frente al absolutismo, nace el derecho penal internacional como una esperanza. Nos quejamos de la africanización de la CPI y es necesario insistir en su recambio. Los crímenes de masa de Colombia y otras latitudes deben pasar a su competencia.

El distinto es el extraño: "desde que existe registro en la historia -dice Zaffaronitodos los males provienen del otro. Aún las calamidades y enfermedades provienen de un ser extraño y extranjero, raro, que perturba, contagia al bueno (rapto de menores hijos de excomunistas), al 'ser nacional'". Entonces, la emergencia para el combate y aniquilamiento del enemigo que atenta contra el ser nacional, esa nebulosa que como forma alienada de la asimilación de lo que es múltiple y diferente en la sociedad, recaba de una el sometimiento, para que se iguale con "uno"; y si no se acepta el sometimiento, pues entonces viene la represión y el exterminio.

El tema está atravesado por factores de acumulación capitalista: “la riqueza no es medio sino fin en sí misma, con lo que avala el triunfo del instinto de muerte (tánatos)". Por ello las modernas constituciones progresistas de Ecuador y Bolivia, entre otras, postulan que una ciencia saludable no tendría por objeto el dominio de la naturaleza, sino la unión con esta.

Estanislao Zuleta en su libro Psicoanálisis y criminología, nos recuerda que "hay una tribu en Nueva Guinea que se llama los Arapesh de la Montaña. Los arapesh se caracterizan porque tienen una economía muy fuertemente socializada, colectivista, hasta tal punto que a un arapesh le está prohibido consumir carne de un animal que él haya cazado; o comer el producto de la yuca o del maíz que hay sembrado en su propio jardín, o consumir el tabaco que haya cultivado. El arapesh solamente trabaja para regalar. Los arapesh creen que los productos del trabajo humano y de la tierra son, en cierto modo, hijos de los trabajadores, que cuando un hombre fecunda una tierra con su trabajo se está realizando lo que ellos asimilan a la sexualidad con la cual obtienen un resultado similar: el nacimiento de un ser que no existía para ellos. Por lo tanto, ellos consideran el producto de su trabajo como su propio hijo y la prohibición del incesto les impide consumir el producto de su trabajo. Así, están obligados de hecho a regalarlos, pero reciben igual regalo de los demás”.

"Es una sociedad, como digo, supremamente firme en el colectivismo y muy interesante por muchos otros aspectos. A un arapesh a quien le preguntaron si existía propiedad sobre la tierra, se quedó tan asombrado como si hubiera escuchado una blasfemia. No solamente no conciben que la tierra pueda ser objeto de una propiedad, sino que conciben las cosas completamente al revés: que los habitantes son propiedad de la tierra, que la tierra está habitada por sus antepasados quienes les imponen una serie de deberes, que los obligan a cultivarla y desyerbarla, porque la tierra es propietaria de esos habitantes. En ella han vivido los antepasados; ella les ha dado el sustento; ella les impone las obligaciones cíclicas de cosechar y de sembrar, por lo tanto, para 
ellos, es una idea completamente absurda la de la propiedad o no propiedad sobre la tierra". Recordamos a Rousseau cuando señaló que el primer hombre que puso cercas a la tierra fue el responsable de miles de crímenes por la propiedad de esta. En La Habana, las Farc y el Gobierno discuten el tema.

La ley primitiva y la ley moderna tienen una primera diferencia, dice Estanislao, en que "los primitivos carecen de todo aparato que les permita imponer la ley; no tienen Estado, ni fuerza armada, ni policía. Nos encontramos con sociedades en las cuales no tenemos nada que se parezca a un cuerpo de policía. El chamán, por ejemplo, que encontramos en la mayor parte de las sociedades primitivas, es una persona que fuera de sus prácticas de danza y curaciones, trabaja como los demás. Esto es así en los nambikwara, en los arapesh, en los bororo, en casi todas las tribus primitivas que no han llegado a la religión. Los chamanes son magos, no son sacerdotes. La religión y la magia son fenómenos completamente diferentes. La magia es una creencia en la omnipotencia de nuestros deseos y nuestras posibilidades de actuar sobre el mundo. Por eso, el mago, el brujo, el hechicero conversa, baila y grita creyendo en la omnipotencia de los hombres, de sus deseos y sus capacidades de actuar sobre las cosas por medio de símbolos, mientras que el sacerdote reza, ruega, hace sacrificios, porque el sacerdote no cree en la omnipotencia de los derechos humanos sino en la omnipotencia de otros seres a los cuales ruega y convoca”. Quizá por ello Borgoglio calló ante los crímenes de la dictadura argentina.

El tema de la relación venganza-punición-política tiene una estrecha relación. Zaffaroni señala cómo "el poder punitivo -con su estructural selectividadcriminaliza a unas pocas personas y las usa para proyectarse como neutralizador de la maldad social que, al igual que la locura, aparecen como irracionales. Se presenta como el poder racional que encierra a la irracionalidad en prisiones y manicomios. Ataviados de este modo, canaliza las pulsiones de venganza, lo que le proporciona una formidable eficacia política, verificada de nuevo en la actualidad, cuando la comunicación masiva glorifica al empresario moral de la venganza para neutralizar los límites al poder punitivo (o sea, en pos del Estado autoritario). La eficacia política del discurso vindicativo no se explica por circunstancias coyunturales, pues se mantiene inalterada a lo largo de la historia del poder punitivo estatal e incluso preestatal".

Y continúa: "Cuando el poder punitivo se descontrola, el fenómeno que genera no se agota -ni mucho menos- en la teoría penal, sino que pasa directamente a la teoría política, porque surge el Estado de policía, autoritario o totalitario, con tendencia al absolutismo".

Partiendo de que en la personalidad paranoica existe la tendencia a proyectar sobre los demás aquello que su yo no acepta, "el Estado moderno siempre presenta una 
tendencia paranoide que llega a la psicosis paranoica cuando proclama la emergencia, siendo entonces un Estado loco que sufre un gravísimo error de significado. La idea base lo invade todo, es víctima e instrumento del miedo, pues cree que todos los males provienen del enemigo, fuente de la emergencia. Cuando el delirio remite, el Estado recobra la razón y acumula experiencia contentora del delirio, cuyo resultado es el conjunto de garantías del derecho constitucional e internacional que va generando una cultura que progresivamente deviene regional y planetaria".

Carl Schmitt lo planteaba ya al calificar la esencia del poder soberano: "Soberano es quien decide sobre el estado de excepción, es decir, quien tiene el poder de elegir al enemigo". El enemigo es el que el político elige como tal, eso basta. La amoralidad es absoluta.

No existe fatalismo biológico en la violencia. Colombia no es genéticamente violenta. Sectores que fueron aparentemente inmunes a procesos de violencia bipartidista, como la Costa Atlántica, presentan en los últimos veinte años fenómenos de violencia inusitada, en especial por la presencia paramilitar.

El tema penitenciario está muy ligado a concepciones económicas de defensa del statu quo y en EEUU, que tiene unas de las poblaciones carcelarias más grandes del planeta, como dice Zaffaroni, "lo utiliza también como presa de cambio para regular su tasa de empleo (quita del mercado a los presos y demanda servicios para mantener el sistema penal)”.

Por lo anterior, es necesario estudiar y construir un nuevo derecho internacional, donde -como dice Feierstein, "uno de los ejes centrales de esta obra pasa por señalar la relevancia que ha tenido y podría tener la creación de un derecho penal internacional como medio para devolver el carácter de persona a los perpetradores de los crímenes de masa, quienes los llevan a cabo no contra el aparato punitivo estatal sino desde el control de dicho aparato y como parte de su propia lógica. El segundo eje, más de carácter criminológico, busca expandir los límites de la explicación del derecho penal para buscar en la psicología o en la etnología una fundamentación del origen, persistencia y sentido de los crímenes de masa".

En esto juega papel medular el Tribunal Permanente de los Pueblos y las ONG defensoras de derechos humanos que luchan por la verdad, la justicia, la reparación y las garantías de no repetición de los crímenes de lesa humanidad.

Tendremos que seguir trabajando en estos temas y penetrar en la judicialización de crímenes económicos y sociales, pues muere más gente por la Ley 100 que por el conflicto armado. Por ello quizá Renán Vega habla de los economistas neoliberales como criminales de lesa humanidad. 
La memoria debe estar presente en esto. La reciente absolución del coronel Álvaro Velandia deja mucho que desear... recuerdo cuando estuve hablando personalmente con el Dr. Hernando Valencia Villa en España, el cual me comentó que tuvo que huir de Colombia por las amenazas de este militar, que fue acusado por la desaparición de Nidya Erika Bautista, docente del M19. El tema tendrá que ir a la jurisdicción internacional, seguramente. El Dr. Valencia, por lo pronto, lleva más de veinte años de exilio.

Quizá tengamos que avanzar en la construcción de muros contra la impunidad y centros de memoria histórica. Ulriksen-Viñar señala: "Hasta hoy en día, en el Sur de América latina no tenemos ningún memorial para los muertos. Hace algunos años, en Lonquen, Chile, fue descubierto, en una mina de cal abandonada, un cementerio de desaparecidos. Casi espontáneamente, el sitio se convirtió en lugar de peregrinaje de viejos, jóvenes, hombres y mujeres que iban a depositar una flor, o simplemente a reconocer en silencio un pedazo de tierra donde dar cabida al pensamiento y la memoria del horror. Al poco tiempo, el gobierno de Pinochet cercó con alambre de púas el lugar y dinamitó la mina donde se encontraron los cuerpos". Pinochet murió en la impunidad, como quedaron las víctimas de esta horrorosa dictadura.

Celebro que la justicia argentina haya asumido la competencia -que le negaron al Juez Garzón- para juzgar los crímenes del franquismo; en Colombia deberíamos luchar para asumir la jurisdicción universal. 